\title{
Article \\ Incidence of Phage Capsid Organization on the Resistance to High Energy Proton Beams
}

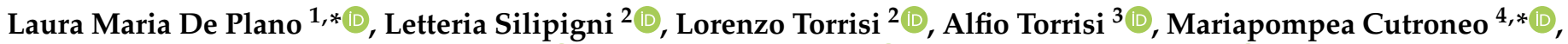 \\ Vladimir Havranek ${ }^{4}$, Anna Mackova ${ }^{4,5} \mathbb{D}^{-}$, Vincenzo Zammuto ${ }^{1}{ }^{(\mathbb{D}}$, Concetta Gugliandolo ${ }^{1}{ }^{\mathbb{D}}$, \\ Maria Giovanna Rizzo ${ }^{1}$, Salvatore P. P. Guglielmino ${ }^{1}$ and Domenico Franco ${ }^{1}$ (D)
}

Citation: De Plano, L.M.; Silipigni, L.; Torrisi, L.; Torrisi, A.; Cutroneo, M.;

Havranek, V.; Mackova, A.;

Zammuto, V.; Gugliandolo, C.; Rizzo,

M.G.; et al. Incidence of Phage

Capsid Organization on the

Resistance to High Energy Proton

Beams. Appl. Sci. 2022, 12, 988.

https://doi.org/10.3390/

app12030988

Academic Editor: Emmanuel

Stratakis

Received: 22 November 2021

Accepted: 14 January 2022

Published: 19 January 2022

Publisher's Note: MDPI stays neutral with regard to jurisdictional claims in published maps and institutional affiliations.

Copyright: (C) 2022 by the authors. Licensee MDPI, Basel, Switzerland. This article is an open access article distributed under the terms and conditions of the Creative Commons Attribution (CC BY) license (https:// creativecommons.org/licenses/by/ $4.0 /)$.
1 Department of Chemical, Biological, Pharmaceutical and Environmental Sciences, University of Messina, 98166 Messina, Italy; vzammuto@unime.it (V.Z.); cgugliandolo@unime.it (C.G.); mgrizzo@unime.it (M.G.R.); sguglielm@unime.it (S.P.P.G.); dfranco@unime.it (D.F.)

2 Department of Mathematical and Computational Sciences, Physical Sciences and Earth Sciences, University of Messina, 98166 Messina, Italy; 1silipigni@unime.it (L.S.); Itorrisi@unime.it (L.T.)

3 Department of Mathematics and Physics "E. De Giorgi"_CEDAD (CEnter of Applied Physics, DAting and Diagnostics), University of Salento, 73100 Lecce, Italy; alfio.torrisi@unisalento.it

4 Department of Neutron Physics, Institute of Nuclear Physics, v.v.i., Husinec-Řež 130, 25068 Řež, Czech Republic; havranek@ujf.cas.cz (V.H.); mackova@ujf.cas.cz (A.M.)

5 Department of Physics, Faculty of Science, J. E. Purkyne University, Pasteurova 3544/1, 40096 Usti nad Labem, Czech Republic

* Correspondence: ldeplano@unime.it (L.M.D.P.); cutroneo@ujf.cas.cz (M.C.)

\begin{abstract}
The helical geometry of virus capsid allows simple self-assembly of identical protein subunits with a low request of free energy and a similar spiral path to virus nucleic acid. Consequently, small variations in protein subunits can affect the stability of the entire phage particle. Previously, we observed that rearrangement in the capsid structure of M13 engineered phages affected the resistance to UV-C exposure, while that to $\mathrm{H}_{2} \mathrm{O}_{2}$ was mainly ascribable to the amino acids' sequence of the foreign peptide. Based on these findings, in this work, the resistance to accelerated proton beam exposure (5.0 MeV energy) of the same phage clones was determined at different absorbed doses and dose rates. Then, the number of viral particles able to infect and replicate in the natural host, Escherichia coli $\mathrm{F}+$, was evaluated. By comparing the results with the M13 wild-type vector (pC89), we observed that 12 IIII 1 phage clones, with the foreign peptide containing amino acids favorable to carbonylation, exhibited the highest reduction in phage titer associated with a radiation damage (RD) of $35 \times 10^{-3} / \mathrm{Gy}$ at 50 dose Gy. On the other hand, P9b phage clones, containing amino acids unfavorable to carbonylation, showed the lowest reduction with an RD of $4.83 \times 10^{-3} / \mathrm{Gy}$ at 500 dose Gy. These findings could improve the understanding of the molecular mechanisms underlying the radiation resistance of viruses
\end{abstract}

Keywords: M13 bacteriophages; engineered phage clones; proton beam radiation; resistance to particles radiation

\section{Introduction}

The last decades have been characterized by viral epidemics that led to the coronavirus pandemic in 2020 and 2021 [1,2]. This places as the main objective of numerous research groups the development of protocols and predictive studies to understand evolutionary ecology and the emergence of new virus variants [3,4]. On the other hand, both epidemiological and patient-based approaches are often late in avoiding pandemic events due to the ability of viruses to quickly gain new infective features during pandemic advancement [5].

Molecular mechanisms, which can occur in natural mutations, determine both the emergence and the spread of new viral variants. In this context, the increase in knowledge could help the protocols of disinfection or virus inactivation (for vaccine development), 
that are often slowed down due to the difficulties related to cultivation techniques and/or high contagiousness.

Bacteriophages (or shortly phages) represent models extremely useful for understanding the molecular mechanisms involved in the stability of viral capsids and the resistance to different stresses. Similar to mammalian virus, phage resistance to environmental stresses is closely related to the protein composition of the external structure, named capsid, which encloses and protects the viral nucleic acid. In addition, it is known that the dynamic rearrangements or disassembly of capsid can affect the nucleic acid release in the host, consequently determining the success or failure of the infectious process [6]. The most common capsid geometries are icosahedral or helical symmetry. In the first case, the nucleic acid of a virus is packaged completely within a geometric shape with 20 sides with morphological units (capsomeres) arising from the interaction of proteins within the repeated structural units [7]. Differently to this, the helical array winds around the nucleic acid, following a similar spiral path, and can require only one nucleocapsid protein. Since a single alteration in the capsid proteins' subunits affect the stability of the entire phage particle, the use of helical phages, engineered to express specific changes on known portions of their protein subunits, could help to identify the cause-effect relationships between specific mutations and new structural rearrangements in the capsid.

M13 phage has been widely used in several applications due to its nontoxic, selfassembling and specific binding properties. The small DNA and use as a vector for constructing phage libraries displaying billions of random peptides on the phage surface, made this phage (together with the other filamentous phages fd and f1) a model system in molecular biology and a versatile tool in genetic engineering and biotechnology [8]. The capsid of M13 phage, characterized by a helical symmetry structure, is mainly constituted by the major coat protein $\mathrm{pVIII}$, which is responsible for the integrity of the phage. Vector systemsbased phage libraries 88 or $8+8$ result in a hybrid structure with a mixture of recombinant and wild-type pVIII molecules on the phage capsid [9]. The use of these random phage libraries is being increased in many biotechnological applications, such as marker discovery in vitro or in vivo [10,11], surface functionalization for biosensors [12-14], as specific scaffolds for tissue-regeneration [15], immunization [16], drug targeting [17,18] and hybrid materials [19-22]. However, since M13 capsid is approximately composed by 2700 copies of the major coat protein $\mathrm{pVIII}$, the virion particles could show a remarkable degree of conformational instability and/or metastability when engineered on pVIII protein [23]. The capsid structure has been suggested to be responsible for the great resistance of M13 to various physical and chemical stresses $[20,24,25]$. Moreover, we recently reported that the addition of foreign peptides in M13-engineered phages modified the spatial distribution of surface charges and the stretching of the entire capsid, affecting their resistance against UV-C exposure and $\mathrm{H}_{2} \mathrm{O}_{2}$ treatment $[26,27]$.

Ionizing radiation can damage biological components though the direct deposition of radiation energy into biomolecules and also indirectly by generating reactive oxygen species (ROS). Hydrogen peroxide $\left(\mathrm{H}_{2} \mathrm{O}_{2}\right)$ and hydroxyl radicals $(\mathrm{HO} \bullet)$ are major oxidizing species produced by the radiolysis of water, and superoxide ions $(\mathrm{O} 2 \bullet-)$ are formed in the presence of dissolved oxygen [28]. Generally, the cytotoxic and mutagenic effects induced by ionizing radiation are thought to be the result of DNA damage caused during the course of irradiation, which includes single-strand breaks (SSB), double-strand breaks (DSB), base modification and sugar modification [29]. The amounts of radiation damage caused by given doses of ionizing radiation for different microorganisms or biomolecules are very similar, although the range of ionizing radiation resistance levels is large [30].

In order to increase our knowledge on the viral resistance to radiations, in this work, the incidence of phage capsid organization of M13-engineered phages on the resistance to high energy proton beams was evaluated. Specifically, the viability of pC89 (M13 wild-type vector) and two engineered phage clones, expressing 9 or 12 additional amino acids in the $\mathrm{N}$-terminal end of $\mathrm{pVIII}$ capsid protein, was determined at different absorbed doses and dose rates. 


\section{Materials and Methods}

\subsection{Bacteriophages}

Engineered phages were obtained from M13 phage libraries, constructed in the vector pC89 [31], by cloning a random DNA insert between the third and fifth codon of the mature pVIII-encoding segments of gene VIII [32]. Specifically, the P9b phage clone was selected from a 9-mer phage library, and it displays the 9 amino acid sequence, QRKLAAKLT, which is fused to the major coat protein (pVIII) and is able to specifically recognize Pseudomonas aeruginosa [33]. In addition, 12III1 phage clone was obtained by screening of 12-mer phage library against anti-Caf1 monoclonal antibody and IgGs from AD-patients, in alternate biopanning cycles, named "double binding" selection. 12III1 display the 12 amino acid sequence, RWPPHFEWHFDD, able to detect IgG levels correlated with Alzheimer disease [34]. All radiation tests were carried out using the insert-less pC89 vector as wild-type virus variant.

\subsection{Phage Propagation}

pC89 and engineered phage clones $(\mathrm{Amp}+)$ were propagated in the bacterial host Escherichia coli strain TG1 (Kan-, Amp-, lacZ-), according to Kay et al. [35] with some modifications for our conditions. For each phage, an overnight culture of E. coli was reinoculated in fresh Luria-Bertani medium (LB) at $250 \mathrm{rpm}$ on a rotary shaker for about $3 \mathrm{~h}$ at $37^{\circ} \mathrm{C}$, until reaching an optical density at $600 \mathrm{~nm}\left(\mathrm{OD}_{600}\right)$ equal to 0.7. After incubation period, E. coli culture was infected with each phage and incubated at $37^{\circ} \mathrm{C}$, in static condition for $15 \mathrm{~min}$ and at $250 \mathrm{rpm}$ on a rotary shaker for $20 \mathrm{~min}$. After incubation, infected E. coli was plated onto LA (Luria-Bertani added with agar $20 \mathrm{~g} / \mathrm{L})$ plates containing ampicillin $(50 \mu \mathrm{g} / \mathrm{mL})$. Plates were incubated overnight at $37^{\circ} \mathrm{C}$ in static condition. From each plate, one colony of E. coli containing phage, was inoculated into $10 \mathrm{~mL}$ of LB medium containing ampicillin $(50 \mu \mathrm{g} / \mathrm{mL})$ and incubated at $250 \mathrm{rpm}$ on a rotary shaker at $37^{\circ} \mathrm{C}$ for $3-4 \mathrm{~h}$, until $\mathrm{OD}_{600}$ equal to 0.2 was reached. After incubation, the culture was added with isopropylthio- $\beta$ galactoside (IPTG, $40 \mu \mathrm{g} / \mathrm{mL})$ and helper phage M13K07 (Kan+) (10 ${ }^{9}$ transduction units per milliliter, $\mathrm{TU} / \mathrm{mL}$ ), incubated at $37^{\circ} \mathrm{C}$, in static condition for $15 \mathrm{~min}$ and at $250 \mathrm{rpm}$ on a rotary shaker for $20 \mathrm{~min}$. After incubation, culture was centrifugated at $8000 \times g$ for $20 \mathrm{~min}$, supernatant removed, replaced with LB medium containing ampicillin $(50 \mu \mathrm{g} / \mathrm{mL})$ and kanamycin $(10 \mu \mathrm{g} / \mathrm{mL})$, and incubated overnight with shaking at $37^{\circ} \mathrm{C}$.

\subsection{Phage Collection}

Phages were collected from the bacterial host culture by means of several centrifugation steps in PEG/NaCl solution, containing 200 g PEG-8000 (polyethylene glycol; SigmaAldrich, Milan, Italy) and $150 \mathrm{~g} \mathrm{NaCl}$ (Sigma-Aldrich, Milan, Italy) per liter. Specifically, culture was centrifuged at $8000 \times g$ for $20 \mathrm{~min}$ at $25^{\circ} \mathrm{C}$, supernatant recovered and mixed with $25 \%(v / v)$ of $\mathrm{PEG} / \mathrm{NaCl}$ solution. The mixture was cooled in ice for $4 \mathrm{~h}$ and precipitated by centrifugation at $15,000 \times g$ for $45 \mathrm{~min}$ at $4{ }^{\circ} \mathrm{C}$. The pellet was recovered, resuspended in $10 \%(\mathrm{v} / \mathrm{v})$ of Tris-buffered saline (TBS, $7.88 \mathrm{~g} / \mathrm{L}$ of Tris hydrochloride and $8.77 \mathrm{~g} / \mathrm{L}$ of $\mathrm{NaCl}$ in deionized water), mixed again with $25 \%(v / v)$ of $\mathrm{PEG} / \mathrm{NaCl}$, cooled in ice for $4 \mathrm{~h}$, and the solution was centrifuged as above. The pellet, containing phage particles, was suspended in $10 \%(v / v)$ of TBS, filtered through $0.22 \mu \mathrm{m}$ pore size membrane (Millipore) and stored at $4{ }^{\circ} \mathrm{C}$.

\subsection{Proton Irradiations}

In total, $200 \mu \mathrm{L}$ suspensions of each phage stocks in Tris-buffered saline (TBS; $7.88 \mathrm{~g} / \mathrm{L}$ of Tris hydrochloride and $8.77 \mathrm{~g} / \mathrm{L} \mathrm{NaCl}$ in deionized water) were exposed at room temperature to proton beams. To this, $200 \mu \mathrm{L}$ solution was capsuled in a small polyethylene (PE) holder with a wall thickness of $25 \mathrm{~mm}$. The holder shape is cylindrical with $10 \mathrm{~mm}$ radius and $637 \mu \mathrm{m}$ height, corresponding to a volume of $200 \mathrm{~mm}^{3}$. Outside of the chamber is located a PIN diode for the measure of the low current rate of particle/s. It was measured $10^{5}$ particle/s and a sensitivity of current of $1 \mathrm{pA}$ corresponding to a rate of 
$100 \mathrm{pulse} / \mathrm{s}$. The attested dose values were further justified by the evaluations obtained using gaf-chromics [36] placed on the front side of the holder hosting the phages.

All irradiations were carried out in the Nuclear Physics Institute of Rez (Czech Republic) using the proton beam extracted in air at the maximum energy of $5 \mathrm{MeV}$ [37]. Protons were accelerated by a Tandetron accelerator and led [38] to a holder placed inside the vacuum chamber containing a YAG Cs scintillator to set the beam size and focus, $\mathrm{Cu}$ mesh to probe the resolution and a small faraday cup to measure the current of proton beam. Finally, protons were extracted from high vacuum to air through $200 \mathrm{~nm} \mathrm{Si}_{3} \mathrm{~N}_{4}$ film, of which density is $3.17 \mathrm{~g} / \mathrm{cm}^{3}$. The proton energy loss in this film is $\mathrm{DE}_{1}=4 \mathrm{keV}$. Protons cross $2 \mathrm{~mm}$ air thickness before hitting the PE holder, losing an energy of $\mathrm{DE}_{2}=16.4 \mathrm{keV}$. Crossing the PE wall thickness protons lose another $\mathrm{DE}_{3}=261.5 \mathrm{keV}$, to reach the solution containing the phages, with a kinetic energy of $4718 \mathrm{keV}$.

To fulfil the demands of uniform irradiation of the solution, the proton irradiation was accomplished using a proton microbeam with a size of $500 \mathrm{~mm} \times 530 \mathrm{~mm}$, which was swept on an area of $24 \mathrm{~mm} \times 20.1 \mathrm{~mm}$. The scan velocity is $1.985 \mathrm{~mm} / \mathrm{s}$, the step resolution is $0.3 \mathrm{~mm}$ and the total number of horizontal sweep lines is 67 . The irradiated surface was $\mathrm{S}=4.8 \mathrm{~cm}^{2}$ and the used proton fluence $\mathrm{F}_{\mathrm{i}}$ ranges between $2.3 \times 10^{7} \mathrm{H}^{+} / \mathrm{sA}$ and $2.3 \times 10^{8} \mathrm{H}^{+} / \mathrm{sA}$. The solution was irradiated by high proton energy at $4718 \mathrm{keV}$ and low energy around $100 \mathrm{keV}$.

\subsection{Dose Absorbed (Da) and Dose Rate}

The dose absorbed by the biological solution containing the phages, $D_{a}$, in terms of energy deposited for mass unit (Gy), was calculated taking into consideration the abovedescribed proton irradiation conditions as follows [39]

$$
D_{a}(\mathrm{~Gy})=F_{i} \times S_{t} \times \frac{1}{r}
$$

where $F_{i}$ is the ion fluence calculated in ions $/ \mathrm{cm}^{2}$ units, $S_{t}$ the total stopping power given in $\mathrm{keV} / \mu \mathrm{m}$ and $r$ the mass density in $\mathrm{g} / \mathrm{cm}^{3}$ of the irradiated solution. Irradiations were performed using doses from 5 up to $500 \mathrm{~Gy}$ and dose rates, obtained dividing for the irradiation time, from 0.00615 up to $0.615 \mathrm{~Gy} / \mathrm{s}$. Doses and dose rates have uncertainties lower than $5 \%$.

\subsection{Phage Titration $(\mathrm{TU} / \mathrm{mL})$}

After proton beam exposure, tenfold serial dilutions of each phage were prepared. Then, $10 \mu \mathrm{L}$ from each dilution sample were dispensed into sterile micro-centrifuge tubes containing $90 \mu \mathrm{L}$ of E. coli TG1 culture at $\mathrm{OD}_{600}$ equal to 0.7 . Tubes were incubated at $37^{\circ} \mathrm{C}$ in static condition for $15 \mathrm{~min}$ and at $250 \mathrm{rpm}$ on a rotary shaker for $20 \mathrm{~min}$. After incubation, $100 \mu \mathrm{L}$ of each phage/E. coli TG1 suspension were dispensed into LA plates containing ampicillin $(50 \mu \mathrm{g} / \mathrm{mL})$ and incubated at $37{ }^{\circ} \mathrm{C}$ overnight. Plates, containing between 30-300 colonies, were counted to derive the number of active viral particles able to infect the host cell and express the transgene. Thus, the active particles were determined by transducing units per milliliter (TU/mL), according to the following Equation (2)

$$
\frac{\mathrm{TU}}{\mathrm{mL}}=\frac{\text { (number of colonies) }}{\text { volume }(0.1 \mathrm{~mL}) \times \text { dilution factor }}
$$

All assays were performed in quintuplicate.

\subsection{Radiation Damage (RD)}

The radiation damage (RD) was defined as the effect of the high energy protons beam on phage ability to infect its host and express the transgene. It represents the logarithmic 
inactivation of phage titer per absorbed dose in Gy and can be derived from the following Equation (3)

$$
\mathrm{RD}=\frac{\log _{10} \mathrm{Ns}(\mathrm{i})-\log _{10} \mathrm{Ns}(\mathrm{r})}{\text { Dose }(\mathrm{Gy})}
$$

where Ns(i) and Ns(r) are M13 particles not irradiated and after irradiation, respectively. In order to exclude any changes due to overall long-term stability of phages, the not irradiated samples followed the same travel and storage of irradiated samples. The significant differences in the RD values were determined by analysis of variance (ANOVA) using adjusted $p$-values at 0.01 and $99 \%$ for family-wise significance and confidence level, respectively.

\section{Results and Discussion}

In order to have a proper proton-solution interaction, each phage solution $(200 \mu \mathrm{L})$ in small polyethylene (PE) holders was treated according to the experimental set-up described in Figure 1.

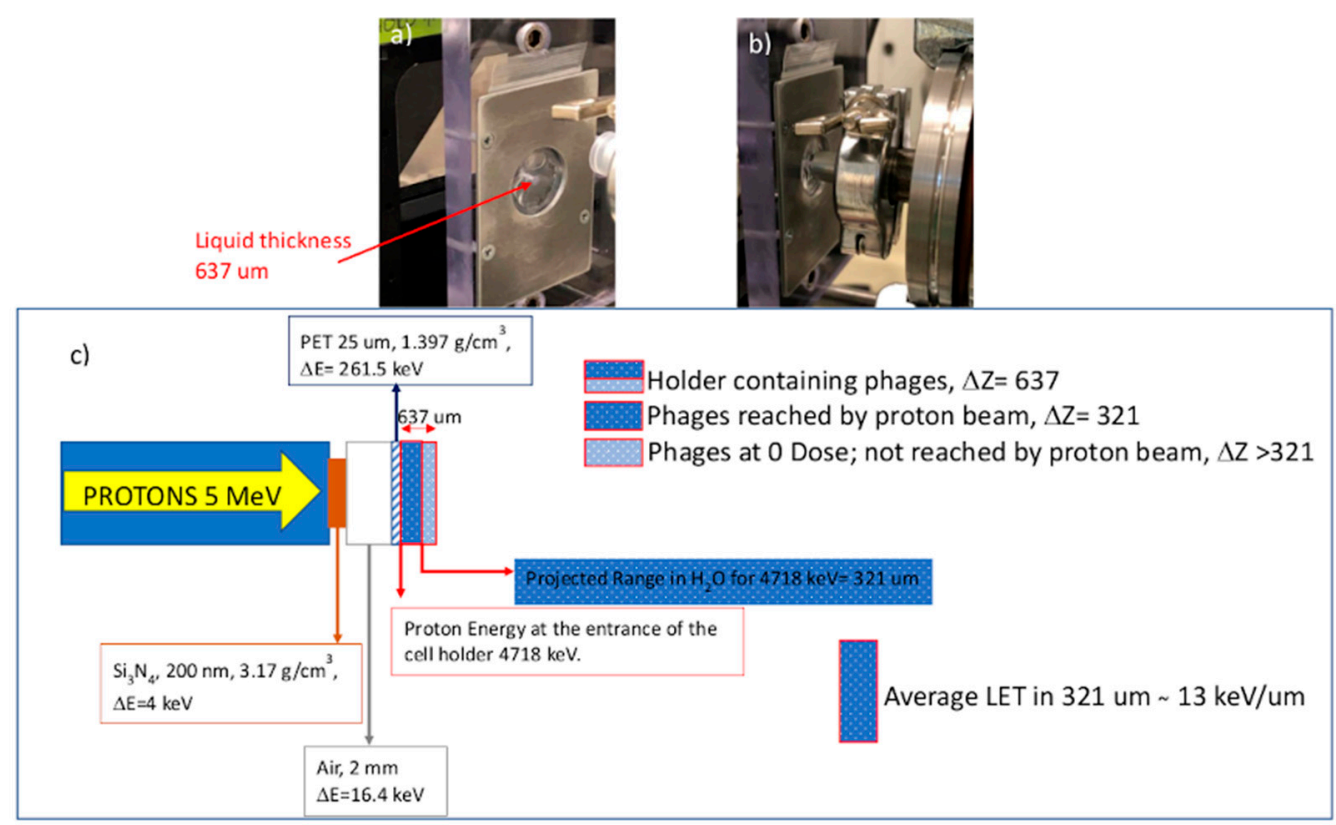

Figure 1. Holder made of PE, containing the phage solution (a), detail of the set-up adopted for the proper proton-solution interaction (b) and scheme of the proton energy loss in the different materials before hitting the phage solution (c).

Since the proton path is affected by the chemical-physical features of the holder, preliminary tests with different materials were carried out to evaluate the proton energy loss before hitting the viral solution (data not shown). In our experimental conditions, the projected ion range in the solution was $321 \mu \mathrm{m}$, thus, only $50 \%$ of the solution thickness was irradiated. To this, the solution holder was subjected to fast oscillations, which, producing liquid mixing, permitted irradiation of the entire solution during the $800 \mathrm{~s}$ irradiation time. Experiments were carried out in the regimes of electron energy loss and nuclear energy loss, respectively, because each phage solution was irradiated by high proton energy (4718 keV) and low energy (around $100 \mathrm{keV}$ ). In the first case, ionizations were mainly produced along the proton path, while in the second case, scissions, atomic collisions and the breaking of chemical bonds occurred.

Figure 2a reports the SRIM simulations [40] of the proton trajectories inside the liquid solution, assumed as "water-like", while Figure $2 \mathrm{~b}$ shows the stopping power trend versus the solution depth, indicating the different stopping at the target surface (electronic) and at the Bragg peak (maximal stopping at the end of ion path). From the latter, it can be deduced that the minimum stopping power is $8 \mathrm{keV} / \mu \mathrm{m}$, while the maximum, at the Bragg 
peak, is $40 \mathrm{keV} / \mu \mathrm{m}$. By considering the shape of the proton stopping power vs. depth, the average weight of its value is about $13 \mathrm{keV} / \mu \mathrm{m}$, which is considered to be the average linear energy transfer (LET) of the proton radiation in the irradiated solution.

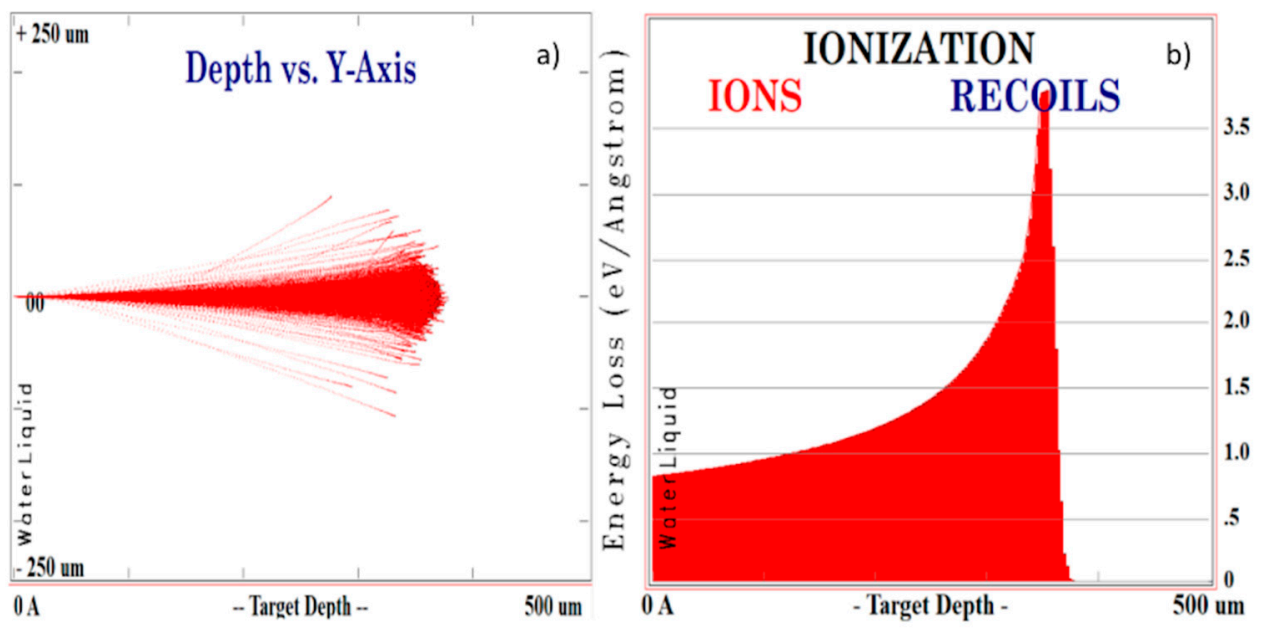

Figure 2. Proton penetration in the water solution (a) and stopping power of the protons along the solution depth (b).

It is known that the proteins are prominently targeted by radiations, which induce oxidation or reduction in the functional groups exposed on the chains [41,42]. Consequently, the resistance to radiation stress could depend on the maintenance of the capsid structure, especially against indirect damage, due to radiolytic $\mathrm{OH}-$ and $\mathrm{H}+$ products resulting from the water radiolysis. In more complex structures, such as that of bacteriophage M13, the pVIII proteins form a tube-like structure around DNA. Specifically, each coat protein is oriented with the $\mathrm{N}$-terminus, located at the outside, and the $\mathrm{C}$ terminus at the inside to interact with the DNA [43]. Moreover, the hydrophobic domain, located in the central part, interlocks the coat protein with those neighboring [44]. Consequently, small variations in protein subunits can affect the stability of the entire phage particle.

To this purpose, two phage clones, engineered to display in pVIII capsid protein foreign peptides of 9 (P9b) and 12 amino acids (12III1), were evaluated for their ability to maintain infectious and replicative properties after exposure to accelerated proton beams at 5.0 MeV energy, 3.8-38 pA beam current, 50-500 Gy absorbed dose and 0.0615-0.615 Gy/s dose rate (Table 1).

Table 1. Used dose and dose rates for phage solution proton irradiation.

\begin{tabular}{ccccc}
\hline \multicolumn{5}{c}{ Dose (Gy) } \\
\hline 50 & 125 & 250 & 375 & 500 \\
\hline 0.0615 & 0.155 & Dose Rate (Gy/s) & 0.615 \\
\hline
\end{tabular}

Although the absorbed doses were high, their administration to the phage solution was given slowly (Table 1), thus, the dose rate was low, giving time to the molecular structures to reorganize and to the biological structures to partially repair the damage suffered.

Phage clones were chosen on the basis of the amino acid sequence of the foreign peptide displayed on the engineered pVIII protein. Specifically, 12III1 foreign peptide contains amino acids with aromatic (4), negatively (3) and positively (3) R-groups that are highly responsive to oxidation products from water radiolysis, such as with $\mathrm{OH}^{-}$addition to the aromatic ring or carbonylation reaction. Moreover, oxidation by reactive oxygen species (ROS) could also include the production of carbonyl groups on the amino acid side 
chain of proline residues. On the other hand, in P9b, the presence of aliphatic amino acids, namely leucine (2) and alanine (2), in foreign peptide should maintain the capsid's integrity and, therefore, the phage clone is less susceptible to oxidative stress. All experiments were carried out using M13 wild-type vector without the peptide insert (pC89) as control. Results on the viability of $\mathrm{pC} 89, \mathrm{P} 9 \mathrm{~b}$ and $12 \mathrm{III} 1$ phages after exposure to proton beam radiation are reported in Table 2 .

Table 2. Active virus particles of pC89, P9b and 12III1, expressed as transducing unit per milliliter of infected E. coli $(\mathrm{TU} / \mathrm{mL})$, at different dose $(\mathrm{Gy})$ of $5 \mathrm{MeV}$ proton irradiation. In brackets are survival percentages compared to exposed phages. Each value has been derived as averages from 5 replicates with standard deviations.

\begin{tabular}{|c|c|c|c|c|c|c|}
\hline \multirow{2}{*}{ Phage Clone } & \multirow{2}{*}{ Exposed } & \multicolumn{5}{|c|}{ Dose (Gy) } \\
\hline & & $50 \mathrm{~Gy}$ & $125 \mathrm{~Gy}$ & $250 \mathrm{~Gy}$ & 375 Gy & $500 \mathrm{~Gy}$ \\
\hline pC89 & $\begin{array}{c}(3.0 \pm 0.14) \times 10^{10} \\
(100 \%)\end{array}$ & $\begin{array}{c}(2.1 \pm 0.3) \times 10^{10} \\
(70 \%)\end{array}$ & $\begin{array}{c}(7.1 \pm 0.27) \times 10^{8} \\
(2.37 \%)\end{array}$ & $\begin{array}{c}(3.0 \pm 0.41) \times 10^{8} \\
(1 \%)\end{array}$ & $\begin{array}{c}(1.1 \pm 0.8) \times 10^{8} \\
(0.37 \%)\end{array}$ & $\begin{array}{c}(1.0 \pm 0.5) \times 10^{7} \\
(0.033 \%)\end{array}$ \\
\hline $\begin{array}{c}\text { P9b } \\
\text { (QRKLAAKLT) }\end{array}$ & $\begin{array}{c}(2.6 \pm 0.21) \times 10^{10} \\
(100 \%)\end{array}$ & $\begin{array}{c}(2.0 \pm 0.25) \times 10^{10} \\
(77 \%)\end{array}$ & $\begin{array}{c}(1.1 \pm 0.17) \times 10^{10} \\
(42.3 \%)\end{array}$ & $\begin{array}{c}(5.0 \pm 0.34) \times 10^{9} \\
(19.2 \%)\end{array}$ & $\begin{array}{c}(2.4 \pm 0.45) \times 10^{9} \\
(9.2 \%)\end{array}$ & $\begin{array}{c}(1.0 \pm 0.49) \times 10^{8} \\
(0.38 \%)\end{array}$ \\
\hline $\begin{array}{c}\text { 12III1 } \\
\text { (RWPPHFEWHFDD) }\end{array}$ & $\begin{array}{c}(3.0 \pm 0.38) \times 10^{10} \\
(100 \%)\end{array}$ & $\begin{array}{c}(5.1 \pm 0.23) \times 10^{8} \\
(17 \%)\end{array}$ & $\begin{array}{c}(3.0 \pm 0.39) \times 10^{7} \\
(0.1 \%)\end{array}$ & $\begin{array}{c}(1.9 \pm 0.5) \times 10^{7} \\
(0.063 \%)\end{array}$ & $\begin{array}{c}(4.7 \pm 0.48) \times 10^{6} \\
(0.0157 \%)\end{array}$ & $\begin{array}{c}(1.4 \pm 0.51) \times 10^{4} \\
(0.00047 \times 10 \%)\end{array}$ \\
\hline
\end{tabular}

Data show that at the maximum absorbed proton dose (500 Gy) the most resistant phage was P9b (0.38\% of survival), while the least resistant was $12 \mathrm{III} 1(0.00047 \%)$. Finally, an intermediate level of resistance was exhibited by the pC89 $(0.033 \%)$. This trend of susceptibility was observed at each dose Gy, and P9b was always the most resistant phage, while the least was $12 \mathrm{III} 1$ (Figure 3a).

a)

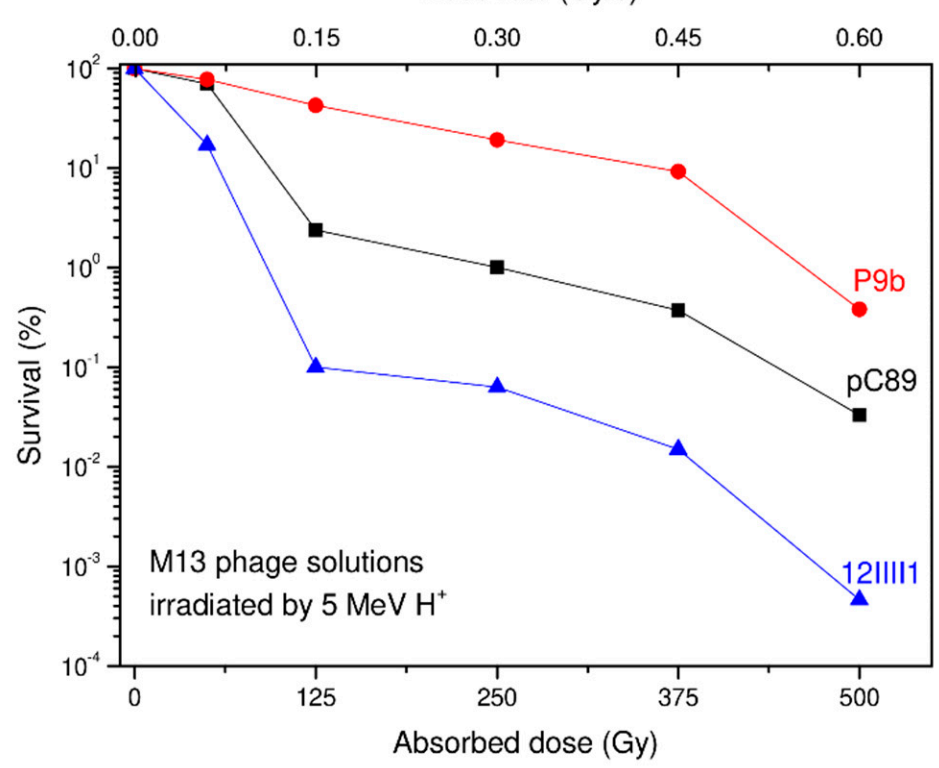

b)

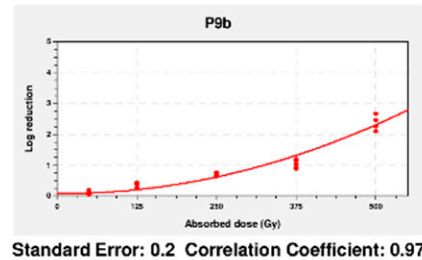

pc89

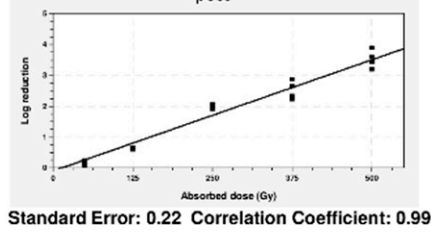

12 III1

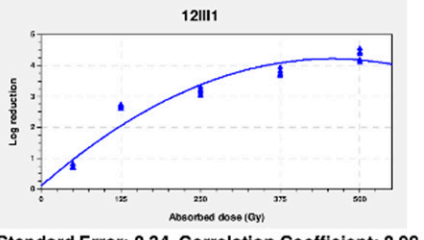

Standard Error: 0.34 Correlation Coefficient: 0.98

Figure 3. Susceptibility trend of $\mathrm{pC} 89,12 \mathrm{III} 1$ and $\mathrm{P} 9 \mathrm{~b}$ to proton beam radiation in terms of survival percentage (a) and logarithmic viability reduction (b).

Since the tested phages have the same DNA, with the exception of the small insert displaying the foreign peptide on the major coat proteins, it is very likely that the difference in susceptibility is due to the presence/absence and amino acid composition of the foreign peptide. The latter does not affect the replication of the phage but determines its susceptibility in the presence of radiation stress. Moreover, since the experimental plan for each phage was carried out in about $800 \mathrm{~s}$ continuum irradiation time, the same trend was 
also found in terms of the dose rate in the range $0.0615-0.615 \mathrm{~Gy} / \mathrm{s}$, as specified in Table 1. Interestingly, when evaluated in terms of logarithmic reduction as a function of the proton absorbed dose, the tested phages showed different trends (Figure 3b). In fact, pC89 showed a linear trend of the logarithmic reduction with increasing proton absorbed dose, whereas the two engineered phages exhibited a quadratic trend with a saturation phase of the log reduction at the maximum tested dose for $12 \mathrm{III} 1$ and a lag phase at the lowest dose for P9b. These findings indicate that the action of resistance to the proton radiation was maintained in P9b up to the dose of $375 \mathrm{~Gy}$, beyond which the phage began to lose vitality; on the other hand, 12III1 showed a loss of vitality at all doses, even higher than that of pC89, revealing an almost absence of resistance already at the first exposure dose of proton radiation. It is known that coat proteins have a critical role both during the infectious process of entry and assembly of the new virion [45]. Consequently, the coat protein structure and its dynamicity during the virus reproduction cycle must be maintained. Our findings show that P9b did not suffer damage (including any lethal mutations) that would interfere with its correct infectious cycle.

Based on Equation (3), we deduced the radiation damage (RD) for the proton beam by the logarithmic values of the phage survival. These findings are supported by the RD ranges for each phage clone between the minimum (50 Gy) and high levels (500 Gy), which are reported in Table 3.

Table 3. Radiation damage ( $\mathrm{RD}, \times 10^{-3} \mathrm{~Gy}^{-1}$ ) for each phage at different doses (Gy) of $5 \mathrm{MeV}$ proton irradiation.

\begin{tabular}{cccccc}
\hline Phage Clone & $\mathbf{5 0} \mathbf{G y}$ & $\mathbf{1 2 5} \mathbf{G y}$ & $\mathbf{2 5 0} \mathbf{G y}$ & $\mathbf{3 7 5} \mathbf{G y}$ & $\mathbf{5 0 0} \mathbf{G y}$ \\
\hline $\mathrm{pC} 89$ & 3.1 & 13 & 8.0 & 6.5 & 6.95 \\
\hline P9b (QRKLAAKLT) & 2.28 & 2.99 & 2.86 & 2.75 & 4.83 \\
\hline 12III1 (RWPPHFEWHFDD) & 35.4 & 24.0 & 12.8 & 10.1 & 10.7 \\
\hline
\end{tabular}

RD was very high in the case of 12III1, arriving at values of the orders of $35 \times 10^{-3} / \mathrm{Gy}$ at 50 dose $\mathrm{Gy}$, and decreasing with increasing exposure doses. These findings agree with those from Figure 3 and confirm the almost total absence of resistance of 12III1 to proton radiation, as evidenced by higher RD values at lower exposure doses. On the other hand, $\mathrm{P} 9 \mathrm{~b}$ showed a low and constant RD value, with a slight increase at the highest dose tested (500 Gy), revealing high resistance to all doses tested. Finally, an intermediate trend was observed for pC89, which showed the maximum RD value at the dose of $125 \mathrm{~Gy}$.

The RD trend of each phage as a function of the absorbed proton dose and the dose rate is shown in Figure 4.

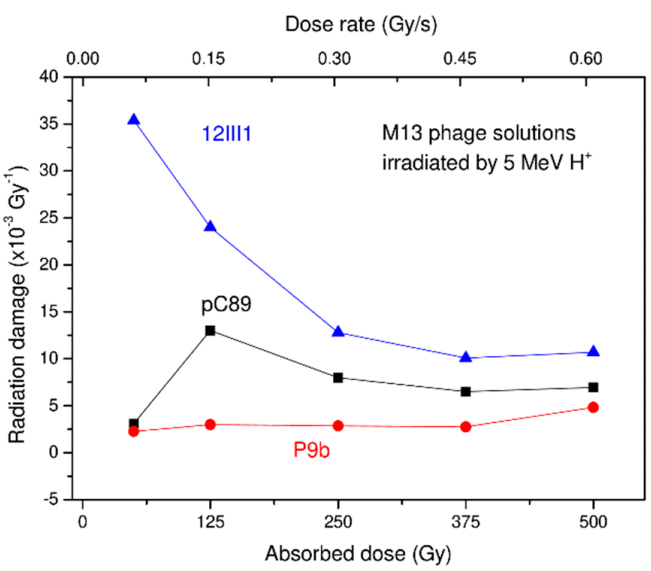

Figure 4. Radiation damage (RD) for each phage as a function of absorbed proton dose and the dose rate. 
Results indicated that, while 12III1 and pC89 reached the maximum RD at 35.4 and 13 dose Gy, respectively, P9b had still not reached the maximum RD value. Moreover, RD values from all phages tended to become closer at the maximum total dose. Since RD represents the logarithmic inactivation of phage titer per absorbed dose in Gy, the more susceptible phages will have high values at low doses, as in the case of 12III1 and pC89, and a negative correlation as the dose Gy is increased, due to the fact that most of the phage titer has already been lost at the first doses. Along with those described above, these results indicated that the resistance to irradiations was probably dependent on the maintenance of the capsid structural integrity. The different behaviours of the three phages exposed to the proton beam could be correlated with a different degree of interaction between $\mathrm{pVIII}-\mathrm{pVIII}$ proteins, due to the peptides exposed in their N-terminus. In a previous work, we observed that the presence of a foreign amino acid sequence on the capsid protein $\mathrm{pVIII}$ of P9b and 12III1 phage clones generated an increase in H-bonds and steric interactions in capsid proteins, resulting in the increased resistance to UV-C radiation damage [26].

The comparison of the susceptibility to the proton beam and UV-C of the three phages is reported in Figure 5.

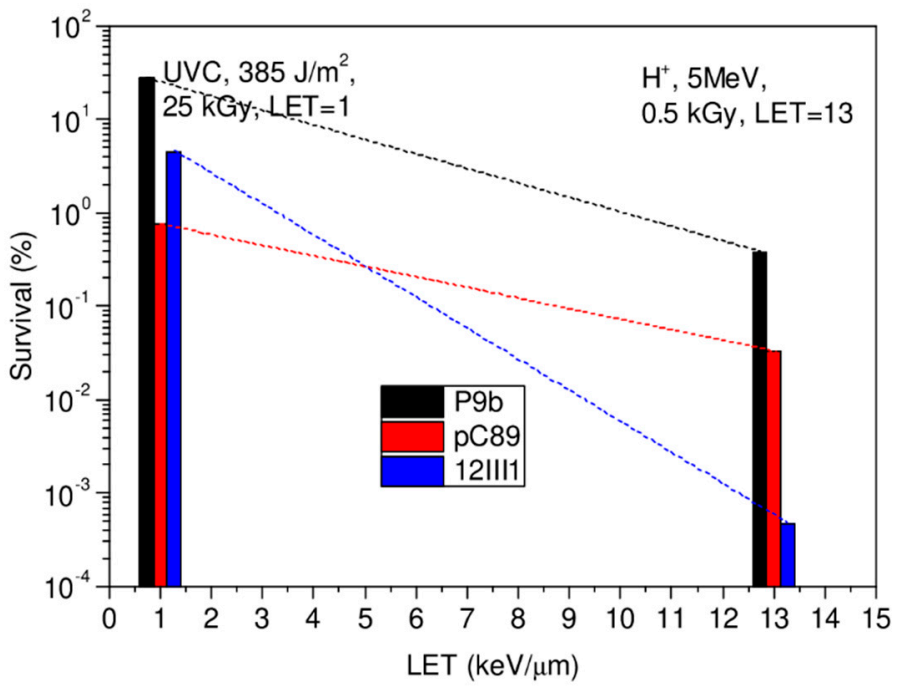

Figure 5. Susceptibility comparison of pC89, P9b and 12III1 phages to proton beam and UV-C.

It is well known that ionizing radiations induce damage proportionally to the radiation LET and the plot of the damage vs. LET represents an important aspect for many experts, especially in the field of Physics, Chemistry, Radiology, Biology and Medicine. It is expected that phage survival decreases with the LET value of the used ionizing radiation, as indicated by the dashed lines in Figure 5. Therefore, a lower dose for protons and a higher dose for photons was needed for the inactivation of the virus.

Although the UV-protons comparison (Figure 5) was performed at comparable doses, the data indicated a noticeable change in the susceptibility to UV-C and proton beam exposure of 12III1, compared to wild-type pC89. The survival ratio P9b/pC89 was 37.6 for UV and 11.5 for protons, while the survival ratio $12 \mathrm{III} 1 / \mathrm{pC} 89$ was 6.13 for UV and 0.014 for protons. Thus, proton beams induced major damage compared with UV photons in all the investigated phages, as expected by the major radiation LET. Concordantly, the survival percentage was reduced from a factor 23 up to a factor 9800 using protons. A possible explanation could be derived from the different nature of the two radiations, in that, when phages are exposed to UV-C radiation, the damage could be predominantly ascribed to the direct effects of absorbed radiation by nucleic acids [46]. The formation of dimers (cyclobutane pyrimidine and pyrimidine) and photoproducts (pyrimidine) has been reported to increase in proportion to the UV-C dose, modifying the DNA structure. On the other hand, when the same phage clones are exposed to the proton beam, they could also be subjected to indirect damage due to $\mathrm{OH}$ - and $\mathrm{H}+$ products resulting from the 
water radiolysis [47]. Differently to P9b, 12III1 foreign peptide, composed by aromatic and other amino acids favorable to carbonylation, could be subjected to a high degree of oxidative modifications and, consequently, a fragmentation of the protein backbone. These findings are in accordance with our previous results, obtained by treating the same phages with $\mathrm{H}_{2} \mathrm{O}_{2}$ [26]. In fact, in these experimental conditions, only P9b showed an increased resistance to induced stress, while no significant difference was recorded between 12III1 and $\mathrm{pC} 89$.

\section{Conclusions}

In order to study the incidence of capsid organization on the resistance to high energy proton beams, M13 wild-type vector and two engineered phage clones, expressing 9 or 12 additional amino acids in the N-terminal end of pVIII capsid proteins, were evaluated.

Results indicated that the radiation damages, induced by different ion doses and dose rates, depended on the amount of ionizing energy transferred to the phages. On the other hand, although the phage viability decreased exponentially with the ion dose, the resistance of each phage to the same dose depended on the amino acid composition of their capsid proteins.

Although we cannot actually distinguish between the electronic and the nuclear damage, the energy released from the radiation could destabilize the entire capsid structure and, therefore, make the nucleic acid more exposed to the radiolitic effects. Our findings showed that 12III1, containing almost exclusively amino acids favorable to carbonylation in foreign peptide, resulted in being the most susceptible to radiation, while $\mathrm{P} 9 \mathrm{~b}$, exposing amino acids not favorable to carbonylation, was the most resistant. These findings suggest that modification in protein subunits could have compromised or further stabilized the entire virion, although further experiments will be performed to separate electronic from nuclear defects in the investigated phage structures. The study of the structure-function and self-assembly of new protein subunits in the capsid, together with the response of the latter in physical stresses, such as ionizing radiation, is needed to understand the molecular mechanisms that underlie the onset and spread of virus variants and, in turn, to allow faster and more effective approaches in the fight against viral disease.

Author Contributions: L.M.D.P., D.F., M.C., C.G., L.T. and S.P.P.G. planned the experiments. L.M.D.P., D.F., M.G.R., V.Z., C.G. and S.P.P.G. performed, acquired and interpreted biological experiments. L.T., L.S., A.T., M.C., V.H. and A.M. performed, acquired and interpreted radiation experiments. L.M.D.P., D.F., M.C., C.G., L.T. and S.P.P.G. analyzed the results and prepared the manuscript. All authors have read and agreed to the published version of the manuscript.

Funding: The irradiation of phages has been realized at the CANAM (Center of Accelerators and Nuclear Analytical Methods) infrastructure LM 2015056.

Institutional Review Board Statement: Not applicable.

Informed Consent Statement: Not applicable.

Acknowledgments: This publication was supported by OP RDE, MEYS, the Czech Republic under the project CANAM OP, CZ.02.1.01/0.0/0.0/16_013/0001812. The authors wish to thank Franco Felici for the kind gift of phage display M13 libraries.

Conflicts of Interest: The authors declare no conflict of interest.

\section{References}

1. Roychoudhury, S.; Das, A.; Sengupta, P.; Dutta, S.; Roychoudhury, S.; Choudhury, A.P.; Ahmed, A.B.F.; Bhattacharjee, S.; Slama, P. Viral Pandemics of the Last Four Decades: Pathophysiology, Health Impacts and Perspectives. Int. J. Environ. Res. Public Health 2020, 17, 9411. [CrossRef]

2. Zhou, P.; Yang, X.L.; Wang, X.G.; Hu, B.; Zhang, L.; Zhang, W.; Si, H.R.; Zhu, Y.; Li, B.; Huang, C.L.; et al. A pneumonia outbreak associated with a new coronavirus of probable bat origin. Nature 2020, 579, 270-273. [CrossRef]

3. Dennehy, J.J. Evolutionary ecology of virus emergence. Ann. N. Y. Acad. Sci. 2017, 1389, 124-146. [CrossRef]

4. Snedden, C.E.; Makanani, S.K.; Schwartz, S.T.; Gamble, A.; Blakey, R.V.; Borremans, B.; Helman, S.K.; Espericueta, L.; Valencia, A.; Endo, A.; et al. SARS-CoV-2: Cross-scale Insights from Ecology and Evolution. Trends Microbiol. 2021, 29, 593-605. [CrossRef] 
5. Excler, J.-L.; Saville, M.; Berkley, S.; Kim, J.H. Vaccine development for emerging infectious diseases. Nat. Med. 2021, 27, 591-600. [CrossRef]

6. Perlmutter, J.D.; Hagan, M.F. Mechanisms of virus assembly. Annu. Rev. Phys. Chem. 2015, 66, 217-239. [CrossRef]

7. Prasad, B.V.V.; Schmid, M.F. Principles of virus structural organization. In Viral Molecular Machines; Rossmann, M.G., Rao, V.B., Eds.; Springer: Boston, MA, USA, 2012; pp. 17-47.

8. Petrenko, V.A. Landscape Phage: Evolution from Phage Display to Nanobiotechnology. Viruses 2018, 10, 311. [CrossRef] [PubMed]

9. Smith, G.P.; Petrenko, V.A. Phage display. Chem. Rev. 1997, 97, 391-410. [CrossRef] [PubMed]

10. Wu, C.H.; Liu, I.J.; Lu, R.M.; Wu, H.C. Advancement and applications of peptide phage display technology in biomedical science. J. Biomed. Sci. 2016, 23, 8. [CrossRef]

11. Gillespie, J.W.; Yang, L.; De Plano, L.M.; Stackhouse, M.A.; Petrenko, V.A. Evolution of a landscape phage library in a mouse xenograft model of human breast cancer. Viruses 2019, 11, 988. [CrossRef] [PubMed]

12. Han, L.; Liu, P.; Petrenko, V.A.; Liu, A.H. A Label-Free Electrochemical Impedance Cytosensor Based on Specific Peptide-Fused Phage Selected from Landscape Phage Library. Sci. Rep. 2016, 6, 10. [CrossRef]

13. Han, L.; Wang, D.; Yan, L.; Petrenko, V.A.; Liu, A. Specific phages-based electrochemical impedimetric immunosensors for label-free and ultrasensitive detection of dual prostate-specific antigens. Sens. Actuators B Chem. 2019, 297, 126727. [CrossRef]

14. Rizzo, M.G.; Carnazza, S.; De Plano, L.M.; Franco, D.; Nicolò, M.S.; Zammuto, V.; Petralia, S.; Calabrese, G.; Gugliandolo, C.; Conoci, S.; et al. Rapid detection of bacterial pathogens in blood through engineered phages-beads and integrated Real-Time PCR into MicroChip. Sens. Actuators B Chem. 2021, 329, 129227. [CrossRef]

15. Yoo, S.Y.; Merzlyak, A.; Lee, S.W. Synthetic phage for tissue regeneration. Mediat. Inflamm. 2014, 2014, 192790. [CrossRef]

16. Bazan, J.; Całkosiński, I.; Gamian, A. Phage display-a powerful technique for immunotherapy: 1. Introduction and potential of therapeutic applications. Hum. Vaccines Immunother. 2012, 8, 1817-1828. [CrossRef] [PubMed]

17. Petrenko, V.A.; Gillespie, J.W.; Xu, H.; O’Dell, T.; De Plano, L.M. Combinatorial avidity selection of mosaic landscape phages targeted at breast cancer cells-an alternative mechanism of directed molecular evolution. Viruses 2019, 11, 785. [CrossRef] [PubMed]

18. Hartman, E.C.; Jakobson, C.M.; Favor, A.H.; Lobba, M.J.; Álvarez-Benedicto, E.; Francis, M.B.; Tullman-Ercek, D. Quantitative characterization of all single amino acid variants of a viral capsid-based drug delivery vehicle. Nat. Commun. 2018, 9, 1385. [CrossRef] [PubMed]

19. Han, L.; Shi, J.; Liu, A. Novel biotemplated $\mathrm{MnO}_{2} 1 \mathrm{D}$ nanozyme with controllable peroxidase-like activity and unique catalytic mechanism and its application for glucose sensing. Sens. Actuators B Chem. 2017, 252, 919-926. [CrossRef]

20. De Plano, L.M.; Scibilia, S.; Rizzo, M.G.; Crea, S.; Franco, D.; Mezzasalma, A.M.; Guglielmino, S.P.P. One-step production of phage-silicon nanoparticles by PLAL as fluorescent nanoprobes for cell identification. Appl. Phys. A 2018, 124, 222. [CrossRef]

21. Torrisi, L.; Guglielmino, S.; Silipigni, L.; de Plano, L.M.; Kovacik, L.; Lavrentiev, V.; Torrisi, A.; Fazio, M.; Fazio, B.; di Marco, G. Study of gold nanoparticle transport by M13 phages towards disease tissues as targeting procedure for radiotherapy applications. Gold Bull. 2019, 52, 135-144. [CrossRef]

22. Henry, K.A.; Arbabi-Ghahroudi, M.; Scott, J.K. Beyond phage display: Non-traditional applications of the filamentous bacteriophage as a vaccine carrier, therapeutic biologic, and bioconjugation scaffold. Front. Microbiol. 2015, 6, 755. [CrossRef] [PubMed]

23. Mateu, M.G. Virus engineering: Functionalization and stabilization. Protein Eng. Des. Sel. 2011, 24, 53-63. [CrossRef]

24. Howorka, S. Molecular assembly in natural and engineered systems. Prog. Mol. Biol. Transl. Sci. 2011, 103, 414.

25. Berchtikou, A.; Sokullu, E.; Nahar, S.; Tijssen, P.; Gauthier, M.A.; Ozaki, T. Comparative study on the inactivation of MS2 and M13 bacteriophages using energetic femtosecond lasers. J. Biophotonics 2020, 13, e202000109. [CrossRef]

26. De Plano, L.M.; Franco, D.; Rizzo, M.G.; Zammuto, V.; Gugliandolo, C.; Silipigni, L.; Torrisi, L.; Guglielmino, S.P.P. Role of Phage Capsid in the Resistance to UV-C Radiations. Int. J. Mol. Sci. 2021, 22, 3408. [CrossRef] [PubMed]

27. Morag, O.; Sgourakis, N.G.; Baker, D.; Goldbourt, A. The NMR-Rosetta capsid model of M13 bacteriophage reveals a quadrupled hydrophobic packing epitope. Proc. Natl. Acad. Sci. USA 2015, 112, 971-976. [CrossRef] [PubMed]

28. Krumova, K.; Cosa, G. Overview of reactive oxygen species. In Singlet Oxygen: Applications in Biosciences and Nanosciences; The Royal Society of Chemistry: London, UK, 2016; Chapter 1; Volume 1, pp. 1-21.

29. Lomax, M.E.; Folkes, L.K.; O'Neill, P. Biological consequences of radiation-induced DNA damage: Relevance to radiotherapy. Clin. Oncol. 2013, 25, 578-585. [CrossRef]

30. Zammuto, V.; Fuchs, F.M.; Fiebrandt, M.; Stapelmann, K.; Ulrich, N.J.; Maugeri, T.L.; Pukall, R.; Gugliandolo, C.; Moeller, R. Comparing spore resistance of Bacillus strains isolated from hydrothermal vents and spacecraft assembly facilities to environmental stressors and decontamination treatments. Astrobiology 2018, 18, 1425-1434. [CrossRef]

31. Felici, F.; Castagnoli, L.; Musacchio, A.; Jappelli, R.; Cesareni, G. Selection of antibody ligands from a large library of oligopeptides express on a multivalente exposition vector. J. Mol. Biol. 2019, 222, 301-310. [CrossRef]

32. Luzzago, A.; Felici, F. Construction of disulfide-constrained random peptide libraries displayed on phage coat protein VIII. Methods Mol. Biol. 1998, 87, 155-164.

33. Carnazza, S.; Foti, C.; Gioffrè, G.; Felici, F.; Guglielmino, S.P.P. Specific and selective probes for Pseudomonas aeruginosa from phage-displayed random peptide libraries. Biosens. Bioelectron. 2008, 23, 1137-1144. [CrossRef] 
34. De Plano, L.M.; Carnazza, S.; Franco, D.; Rizzo, M.G.; Conoci, S.; Petralia, S.; Nicoletti, A.; Zappia, M.; Campolo, M.; Esposito, E.; et al. Innovative IgG biomarkers based on phage display microbial amyloid mimotope for state and stage diagnosis in Alzheimer's disease. ACS Chem. Neurosci. 2020, 11, 1013-1026. [CrossRef]

35. Kay, B.; Winter, J.; McCafferty, J. Phage Display of Poplides and Proteins: A Laboratory Manual; Academic Press: San Diego, CA, USA, 1996

36. Torrisi, L.; Havranek, V.; Cutroneo, M.; Torrisi, A. Gafchromic HD-V2 investigations using MeV ion beams in vacuum. Radiat. Eff. Defects Solids 2019, 174, 1063-1075. [CrossRef]

37. Nuclear Physics Institute CAS, Rez, Czech Republic. 2021. Available online: http://www.ujf.cas.cz/en/research-development/ large-research-infrastructures-and-centres/canam/about-the-project/ (accessed on 15 November 2021).

38. Cutroneo, M.; Havranek, V.; Torrisi, A.; Mackova, A.; Malinsky, P.; Slepicka, P.; Sofer, Z.; Torrisi, L. Polydimethylsiloxane-graphene oxide composite improving performance by ion beam irradiation. Surf. Interface Anal. 2020, 52, 1156-1162. [CrossRef]

39. Torrisi, L.; Silipigni, L.; Manno, D.; Serra, A.; Nassisi, V.; Cutroneo, M.; Torrisi, A. Investigations on graphene oxide for ion beam dosimetry applications. Vacuum 2020, 178, 109451. [CrossRef]

40. Ziegler, J.F.; Ziegler, M.D.; Biersack, J.P. SRIM-The stopping and range of ions in matter. Nucl. Instrum. Methods B 2010, 268, 1818-1823. [CrossRef]

41. Chang, R.L.; Stanley, J.A.; Robinson, M.C.; Sher, J.W.; Li, Z.; Chan, Y.A.; Omdahl, A.R.; Wattiez, R.; Godzik, A.; Matallana-Surget, S. Protein structure, amino acid composition and sequence determine proteome vulnerability to oxidation-induced damage. EMBO J. 2020, 39, e104523. [CrossRef] [PubMed]

42. Reisz, J.A.; Bansal, N.; Qian, J.; Zhao, W.; Furdui, C.M. Effects of ionizing radiation on biological molecules-mechanisms of damage and emerging methods of detection. Antioxid. Redox Signal. 2014, 21, 260-292. [CrossRef]

43. Stopar, D.; Spruijt, R.B.; Wolfs, C.J.; Hemminga, M.A. Protein-lipid interactions of bacteriophage M13 major coat protein. Biochim. Biophys. Acta 2003, 1611, 5-15. [CrossRef]

44. Vos, W.L.; Schor, M.; Nazarov, P.V.; Koehorst, R.B.M.; Spruijt, R.B.; Hemminga, M.A. Structure of membrane-embedded M13 major coat protein is insensitive to hydrophobic stress. Biophys. J. 2007, 93, 3541-3547. [CrossRef]

45. Hemminga, M.A.; Vos, W.L.; Nazarov, P.V.; Koehorst, R.B.; Wolfs, C.J.; Spruijt, R.B.; Stopar, D. Viruses: Incredible nanomachines. New advances with filamentous phages. Eur. Biophys. J. 2010, 39, 541-550. [CrossRef] [PubMed]

46. Sommer, R.; Pribil, W.; Appelt, S.; Gehringer, P.; Eschweiler, H.; Leth, H.; Cabaj, A.; Haider, T. Inactivation of bacteriophages in water by means of non-ionizing (UV-253.7 nm) and ionizing (gamma) radiation: A comparative approach. Water Res. 2001, 35, 3109-3116. [CrossRef]

47. Horneck, G.; Klaus, D.M.; Mancinelli, R.L. Space microbiology. Microbiol. Mol. Biol. Rev. 2010, 74, 121-156. [CrossRef] [PubMed] 